\title{
Comparative Study on Current and Voltage Controlled Voltage Source Converter based Variable Speed Wind Generator
}

\author{
K.E. Okedu, R. Takahashi, and J. Tamura \\ Department of Electrical and Electronic Engineering \\ Kitami Institute of Technology, \\ I65 Koen-Cho, 090-8507, Hokkaido, Japan. \\ E-mail: kenokedu@yahoo.com
}

\author{
S.M. Muyeen \\ Department of Electrical Engineering \\ The Petroleum Institute \\ Abu Dhabi, UAE.
}

\begin{abstract}
Different structure and control algorithm can be used for control of power converter. One of the most common control techniques is decouple proportionate integral (PI) control of output active and reactive power to improve dynamic behavior of wind turbine. In this paper, a new current controlled voltage source converter (CC-VSC) scheme is proposed to control both the rotor and grid side converters of DFIG. The performance is verified by comparing the results with voltage controlled voltage source converter (VC-VSC) scheme. The earlier scheme offers the advantage of reduction of the number of PI controllers used in the rotor side converter without degrading dynamic and transient performances. Moreover, DC-link protection scheme can be omitted using the proposed CC-VSC based DFIG control, which reduces overall cost of the system. Simulation analysis by using PSCAD/EMTDC is carried out to find out the effectiveness of the proposed CC-VSC based control scheme of DFIG over the VC-VSC based control scheme.
\end{abstract}

Keywords-current controlled voltage source converter; voltage controlled voltage source converter; grid fault; doubly fed induction generator; wind energy; protection system.

\section{INTRODUCTION}

Wind energy conversion systems have quickly evolved over the last decades, this is because is one of the extra ordinary sources of renewable energy. Therefore, efficient and reliable exploitation tools are necessary to make these installations more profitable. However, due to its clean character and free availability the growth of wind energy has developed rapidly [1-3].

It was shown in [4], that the control strategies of the variable wind turbine has a major effect on the wind turbine and the electric loads, meaning whatever the kind of wind turbine, the control strategy remains a key factor [5]. In the last $15 y e a r s$, the use of doubly fed induction machines in modern variable speed wind turbines has increased rapidly. This development has been driven by the cost reduction as well as the low-loss generation of Insulated Gated Bipolar Transistors (IGBT) [6]. The doubly fed induction generator (DFIG) with a power converter is a common and efficient configuration to transfer the mechanical power from the variable speed rotor to a constant frequency electrical grid $[1,7]$. The DFIG includes an induction generator with slip ring, a partial scale power electronic converter and a DC-link capacitor. The power electronic converter of the DFIG which encompasses a back to back AC-DC-AC voltage source converter has two main parts; grid side converter (GSC) and the rotor side converter (RSC). The GSC helps to maintain a constant DC-link voltage, and also to supply reactive power to the grid during grid fault. The RSC controls the active and reactive power of the DFIG. The DFIG power converter only processes slip power, therefore it is designed in partial scale and just about $20-30 \%$ of the generator rated power $[2,8]$, which makes it attractive from economical point of view.

This paper presents a comparative study between a new coordinated control scheme using current controlled voltage source converter (CC-VSC) and voltage controlled voltage source converter (VC-VSC). The proposed CC-VSC based DFIG can operate well with minimum number of PI controllers in rotor side converter and without the support of DC-link protection scheme, compared to the VC-VSC. Moreover, the intricacy of the controller design can be reduced considerably in the CC-VSC. The two-mass model was considered for the wind generator, as it has great influence on the fault analysis [9]. Simulations were carried out using PSCAD/EMTDC [10] for a three line to ground fault (severe case) in the considered model system, to observe the effectiveness of both schemes. The model system, topology, machine and network parameters, fault time, duration of the fault are exactly the same in the comparative study of both schemes and hence the performance of the proposed scheme can be observed easily.

\section{DYNAMIC MODEL OF WIND TURBINES BASED ON DFIG}

The aerodynamic wind turbine model and the model system considered in this study are described in the following subsections.

\section{A. Wind Turbine Model}

The mechanical power captured from the wind and the mechanical torque developed by the wind turbine shaft can be 
calculated using the well-know aerodynamic equations (1) and (2), addressed in [11-13]:

$$
\begin{aligned}
& P_{m}=\frac{1}{2} A \rho V^{3} C_{p}(\lambda, \beta) \\
& T_{m}=\frac{P_{m}}{\omega_{m}}=\frac{1}{2} A \rho V^{2} C_{p}(\lambda, \beta) \frac{R}{\lambda}
\end{aligned}
$$

Where,

$$
\begin{aligned}
T_{m} & =\text { Mechanical torque }(\mathrm{N} . \mathrm{m}) \\
P_{m} & =\text { Mechanical power }(\mathrm{W}) \\
A & =\text { Swept area by the turbine rotor }\left(\mathrm{m}^{2}\right) \\
R & =\text { Turbine rotor radius }(\mathrm{m}) \\
V & =\text { Wind speed }(\mathrm{m} / \mathrm{s}) \\
C_{p} & =\text { Power coefficient, } \\
\rho & =\text { Air density }\left(\mathrm{kg} / \mathrm{m}^{3}\right) \\
\lambda & =\text { Tip speed ratio }\left(\omega_{\mathrm{m}} \mathrm{R} / V\right) \\
\omega & =\text { Angular speed of wind turbine }(\mathrm{rad} / \mathrm{s}) \\
\beta & =\text { Blade pitch angle }(\text { degree })
\end{aligned}
$$

Details of the wind turbine modeling equations of the DFIG used in the study and the wind turbine characteristic shown in Fig. 1 can be referred to in [11-13].

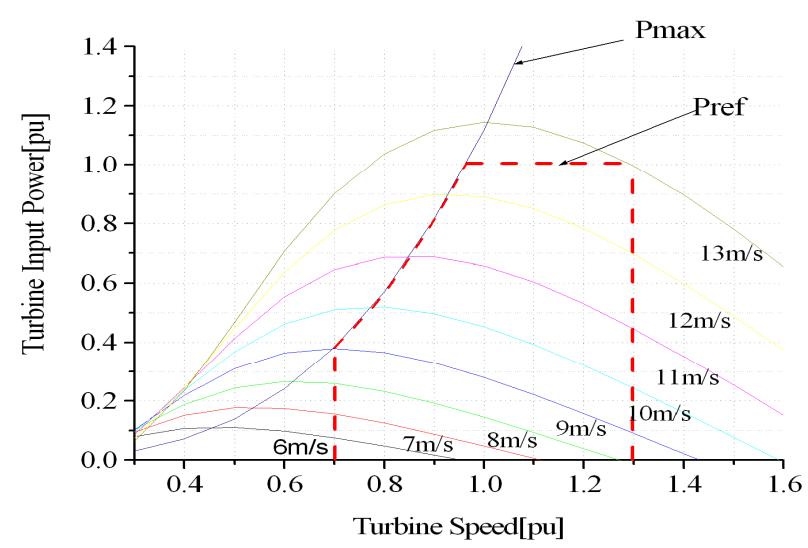

Fig.1 Turbine characteristic with maximum power point tracking (for VSWT)

\section{B. Model System}

The model system used for the comparative study of the CC-VSC and the VC-VSC is shown in Fig. 2 [14]. Aggregated DFIG model of 50MW capacity, connected to an infinite bus was considered for fast computing. Details of the generator parameters and excitation circuits of the DFIG are in [11-13].

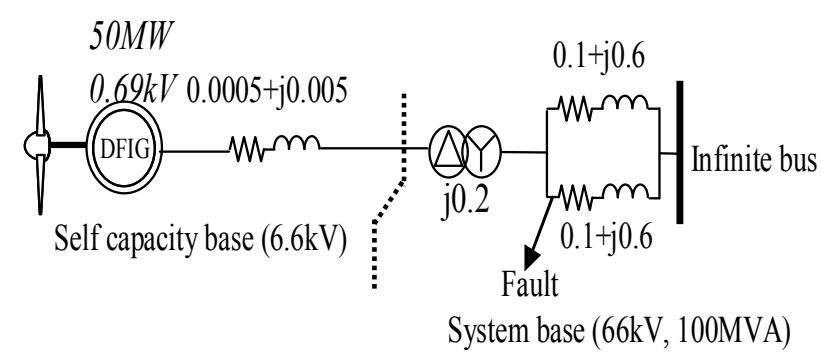

Fig.2 Model system

\section{EFFECT OF GRID FAULT ON DFIG WIND TURBINE}

If there is no protection system, the DFIG can suffer from large transient currents in the stator during a grid fault since its stator circuit is directly connected to the grid. Because of the magnetic coupling between the stator and the rotor, the stator transient is transmitted to the rotor, resulting in both large rotor currents and voltages during the grid fault. Furthermore, the surge following the fault includes a rush of power from the rotor terminals towards the rotor side converter. Therefore there can be a possibility that the desired rotor voltage cannot be maintained and thus the rotor currents cannot be controlled. This means that the rotor side converter can reach to its operating limit and as a consequence it may lose the independent control of real and reactive powers during the grid fault. On the other hand, as the grid voltage drops in the fault moment, the grid side converter is not able to transfer the power supplied from the rotor side converter to the grid, and therefore, the excess energy is stored in the DC-link capacitor, resulting in rapid increase of the DC-bus voltage.

It is therefore necessary to protect the frequency converters against overcurrents, the rotor of the generator against overvoltage and the DC-link against overvoltage. The protection system needs to monitor several signals such as rotor current and the DC-link voltage. When at least one of the control input signals exceeds its respective relay setting, the protection is activated.

A simple protection approach to the problems due to voltage dips of the DFIG under grid fault is to connect a crowbar circuit to the rotor [15-17]. The crowbar short-circuits the rotor when the DC-link voltage $\mathrm{V}_{\mathrm{dc}}$ exceeds $\mathrm{V}_{\mathrm{dc} \text {-max }}$ and the inverter connected to the rotor is protected. The crowbar protection is an insertion of external resistance to the rotor via the slip rings. The value of the crowbar resistance is dependent on the generator condition.

An alternative to the crowbar is to connect a protective device between the inverter and converter of the DFIG as used in the VC-VSC DFIG control [11, 12]. A comparative study between the two protection schemes has been reported in [18], with the conclusion that the latter protection scheme, is preferred to the former protection scheme due to less 
components involved and simple switching circuitry.

The DC-link protection scheme can be omitted during grid fault in the proposed CC-VSC based DFIG strategy as shown in the simulation result.

\section{Current Controlled Voltage Source CONVERTERS STRATEGY FOR DFIG SYSTEM}

The schematic diagram of DFIG including the proposed current controlled voltage source converter is shown in Fig. 3.

The command signals for the rotor side and the grid side controllers are also shown in Fig 3. The mathematical validation of the converters control is described below.

The stator field orientation control is based the stator d-q model, where the reference frame rotates synchronously with respect to the stator flux, with the d-axis of the reference frame instantaneously overlapping the axis of the stator winding flux. Thus, $\omega=\omega_{e}$ and $\lambda_{q s}=0$. Hence in such reference frame selection, the machine dynamic equations can be written as $[19,20]$ :

$$
\begin{aligned}
& V_{d s}=r_{s} i_{d s}+\frac{d \lambda_{d s}}{d t} \\
& V_{q s}=r_{s} i_{q s}+\omega_{e} \lambda_{d s} \\
& \lambda_{d s}=L_{s} i_{d s}+L_{r} i_{d r} \\
& \lambda_{q s}=0=L_{s} i_{q s}+L_{r} i_{q r}
\end{aligned}
$$

Where, $V_{d s}, V_{q s}$, are the d- and q- axis stator voltage, $\lambda_{d s}$, $\lambda_{q s}$, are the d- and q- axis stator winding flux, $i_{d s}, i_{q s}$, are d- and q- stator current, $i_{q r}$ and $i_{d r}$ are d- and q- axis rotor currents (A) respectively, $L_{s}$ and $L_{r}$ are the stator leakage and rotor self inductances $(\mathrm{H}), \omega_{e}$ is the electrical angular velocity $(\mathrm{rad} / \mathrm{s})$, and $V_{s}$ is the magnitude of the stator phase voltage $(\mathrm{V})$.

Since the d-axis of the reference frame is the instant axis of the stator winding flux, the phase angle of the stator voltage is generally not a constant in the reference frame, although its frequency and magnitude are constants constrained by the power system. The electromagnetic torque and stator active power can be derived as

$$
\begin{aligned}
& T_{e}=\frac{3}{2} \frac{P}{2} \lambda_{d s} i_{q r} \\
& P_{s}=\frac{3}{2} \frac{P}{2} \omega_{e} \lambda_{d s} i_{q r}
\end{aligned}
$$

Also in the DFIG, the level of the stator flux remains approximately unchanged, restricted by the constant magnitude and frequency of the stator voltage. Therefore, as can be seen from (5), the torque control can be achieved by controlling the rotor current component orthogonal to the stator winding flux. Then from (6), stator active power is subsequently controlled.
From (1) and (2), with the stator flux remaining unchanged, the reactive power can be derived as

$$
Q_{s}=\frac{3}{2} \frac{P}{2} \omega_{e} \lambda_{d s} i_{d s}
$$

Grid side converter keeps the DC-link voltage of capacitor constant regardless of the magnitude and direction of rotor power. Neglecting power losses in the converter, capacitor current can be described as follows:

$$
i_{d c}=C \frac{d V_{d c}}{d t}=\frac{3}{4} m i_{\mathrm{gcd}}-i_{d c r}
$$

Where $i_{\text {gcd }}$ stands for the $d$-axis current flowing between the grid and grid side converter $(A), i_{d c r}$ is the rotor side DC current $(A), \mathrm{C}$ is the DC-link capacitance $(F)$ and $m$ is the pulse width modulation index of the grid side converter.

The reactive power flow into the grid from the grid side converter can be expressed as:

$$
Q_{g}=\frac{3}{2} V_{g} i_{g c q}
$$

Where $\mathrm{V}_{\mathrm{g}}$ is the magnitude of the grid phase voltage $(V)$ and $\mathrm{i}_{\mathrm{gcq}}$ is $q$-axis current of grid side converter $(A)$. Therefore, it is seen from (10) and (11), by adjusting $i_{\text {gcd }}$ and $i_{\text {gcq }}$, DC-link voltage and $\mathrm{Q}_{\mathrm{g}}$ can be controlled respectively.

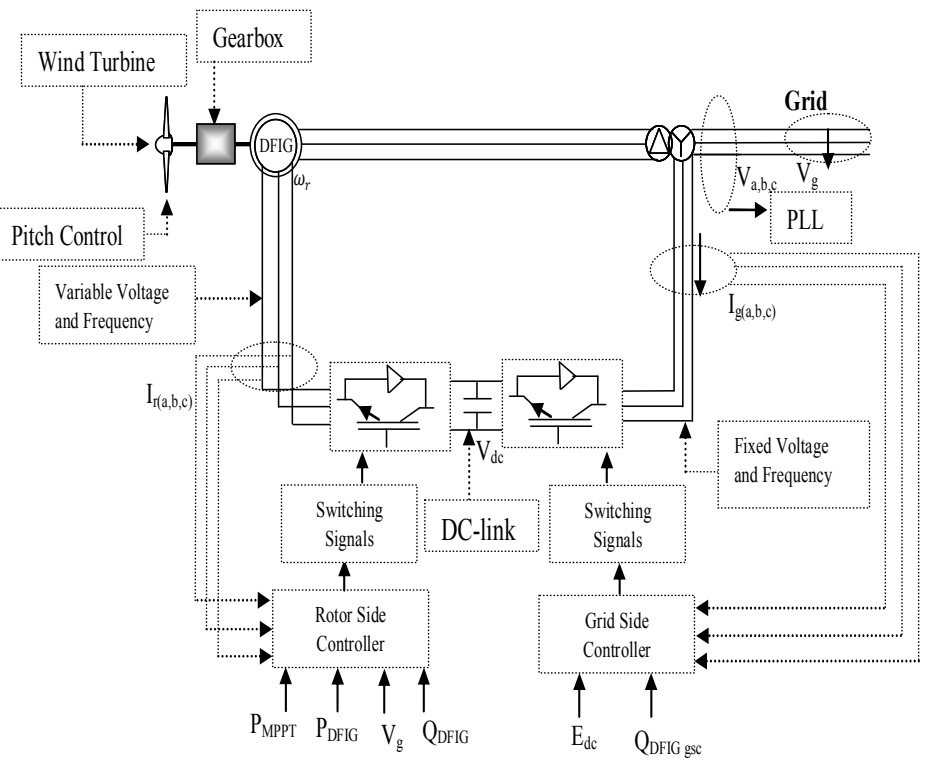

Fig. 3 DFIG with current controlled voltage source converters

\section{A. Rotor Side Converter Control}

In the rotor side converter (RSC) control shown in Fig. 4, the maximum power point tracking $\mathrm{P}_{\mathrm{MPPT}}$ of the wind turbine is compared to the grid power of the DFIG $\mathrm{P}_{\text {DFIG }}$ to determine the reference signal for active power control. A comparator is used to determine the reference signal of the active and reactive 
power control during normal and fault conditions of the DFIG based on the grid voltage. During normal operation, when the grid voltage is above $0.9 \mathrm{pu}$, the reference signal of the DFIG real power is the $\mathrm{P}_{\mathrm{MPPT}}$ of the wind turbine. The reference signal for the DFIG reactive power in normal operation is the difference between the grid voltage $(\mathrm{pu})$ and 1.0pu. The error signals are then passed through PI controllers. During grid fault, when the grid voltage is less than $0.9 \mathrm{pu}$, the comparator regulates the signal by switching the reference signals of the DFIG real and reactive power to zero. In this case, the wind turbine power is reduced during the grid fault, thus this helps to mitigate the overvoltage that is normally experienced in the DC-link in conjunction with the CC-VSC control strategy. The two reference signals from the controller are then converter from dq to abc through the rotor angle calculated from the phase lock loop (PLL). The reference rotor currents ${ }^{*} I_{\text {rabc }}$ are

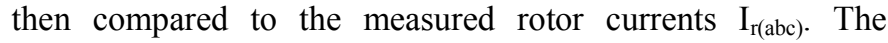
resultant signal is then compared with a carrier signal to generate the switching signals for the insulated gate bipolar transistors (IGBTs) in the RSC. It can be noticed that the use of second PI controller is not necessary in the CC-VSC compared to the VC-VSC. Also, the dq to abc transformation is only once instead of twice as used in the VC-VSC. Thus the intricacies of the controller design are reduced.

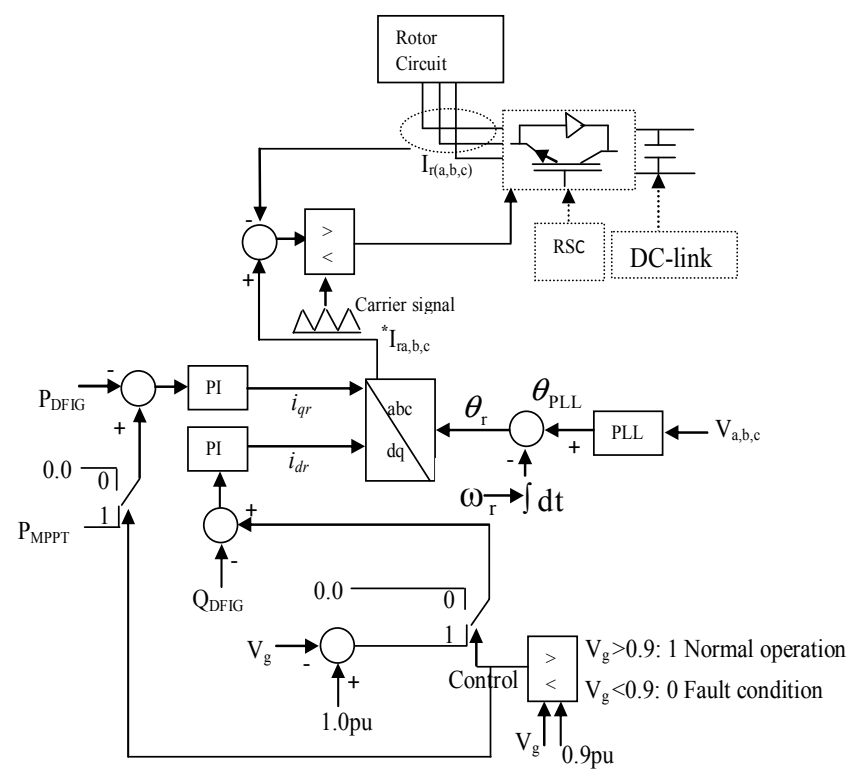

Fig. 4 Block diagram of rotor side converter

\section{B. Grid Side Converter Control}

For the grid side converter (GSC) in Fig. 5, the reference signal for the DC-link voltage and the reactive power of the grid side converter are passed through two PI controllers. The reference signals are then transformed from dq to abc through the stator angle theta. The generated reference signals $* \mathrm{I}_{\text {gabc }}$ are then compared to the measured stator currents $I_{g(a b c)}$. The effective signals are then passed through a second PI, before comparing with a carrier signal to generate the reference switching signals for the IGBTs in the GSC.

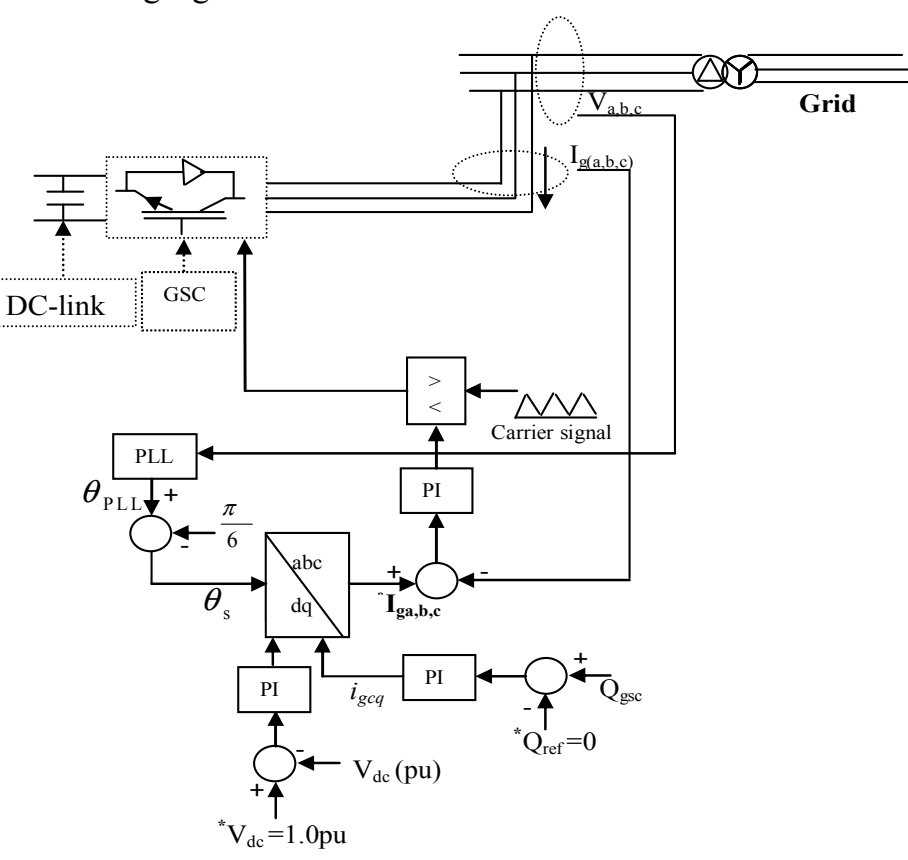

Fig. 5 Block diagram of grid side converter

\section{Voltage Controlled Voltage Source CONVERTERS STRATEGY FOR DFIG SYSTEM}

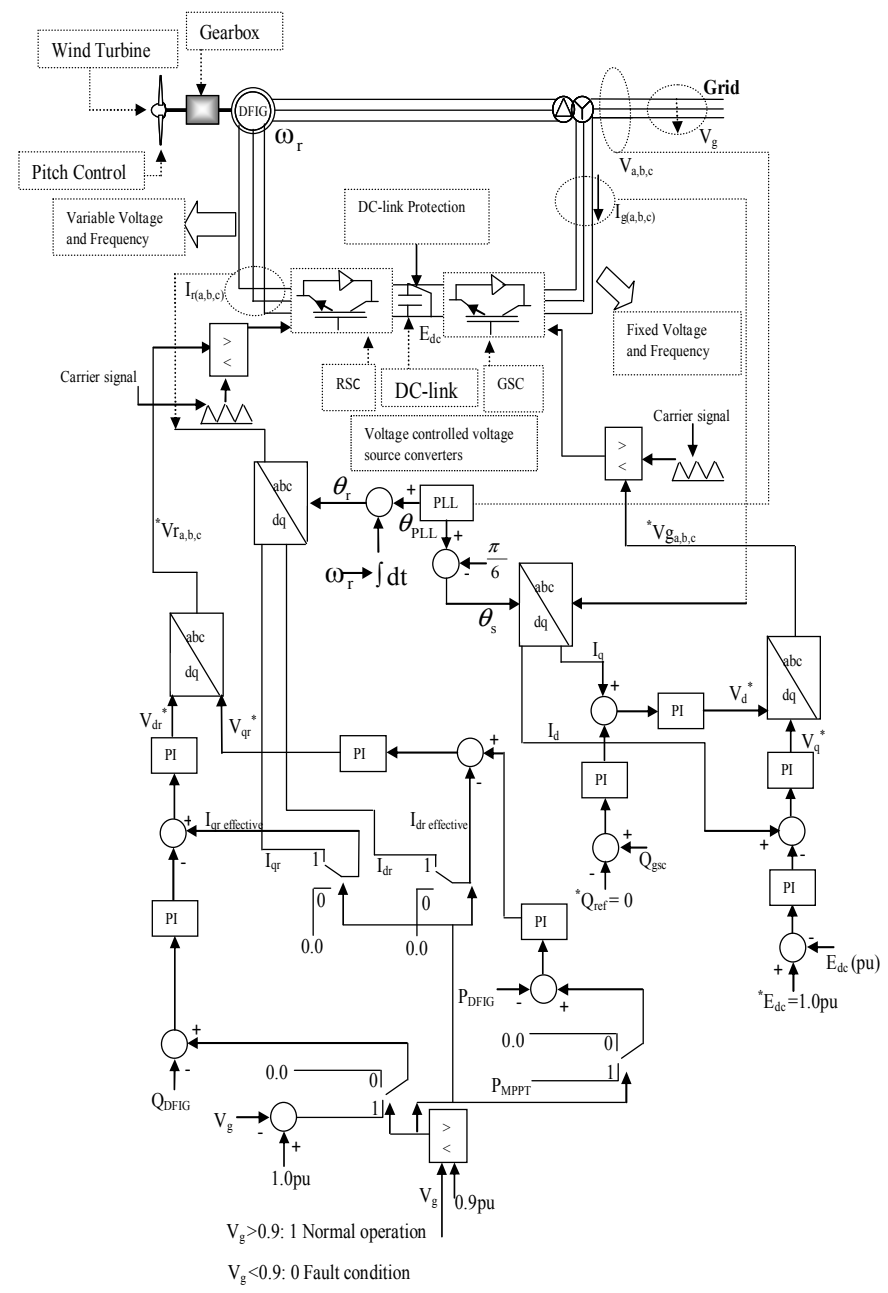

Fig. 6 DFIG with voltage controlled voltage source converters 
The block diagram for the voltage controlled voltage source converter based DFIG is shown in Fig. 6 for the rotor and grid side converters respectively.

\section{A. Rotor side converter control}

In normal operation (when the grid voltage $V_{g}>0.9$ ), the RSC regulates the developed electric power $\left(P_{D F I G}\right)$ and delivers/absorbs reactive power as well by the DFIG. In Fig. 6, $\theta_{P L L}$ is the angle of the phase lock loop (PLL), and $\theta_{r}$ is the effective angle for the abc-dq0 and the dq0-abc transformations. The rotor side converter controls the terminal (grid) voltage to $1.0 \mathrm{pu}$. The d-axis current controls the active power, while the q-axis current controls the reactive power. After a dq0-to-abc transformation, $V_{d r}{ }^{*}$ and $V_{q r}{ }^{*}$ are sent to the PWM signal generator. Thus, ${ }^{*} \mathrm{Vr}_{\mathrm{abc}}$ is the three-phase voltage reference for the rotor side converter, that is obtained for the IGBTs switching as shown in Fig. 6.

\section{A. Grid side converter control}

Fig. 6 also shows the control block for the GSC control, where PLL provides the angle $\theta_{P L L}$ and $\theta_{s}$ is the effective angle for the abc-to-dq0 (and dq0-to-abc) transformation. The GSC system of the DFIG is used to regulate the DC-link voltage $\left(E_{d c}\right)$ to $1.0 \mathrm{pu}$. The d-axis current controls the DClink voltage, while the q-axis current controls the reactive power of the grid side converter. After a dq0-to-abc transformation, $V_{q}{ }^{*}$ and $V_{d}{ }^{*}$ are sent to the PWM signal generator. Finally ${ }^{*} \mathrm{Vg}_{\mathrm{abc}}$ is obtained as a three phase voltage reference for the GSC output.

\section{SimUlation RESUlTS AND DisCUSSION}

Simulation analyses were carried out in PSCAD/EMTDC for two cases. In the first case, the VC-VSC based scheme is considered to control the DFIG. In the second case, the proposed CC-VSC based scheme was considered also for the DFIG control. The model system, network and machine parameters, fault conditions, are exactly the same to show the effectiveness of the schemes in the comparative study.

A three line to ground fault as shown in the model system (Fig. 2) occurs at $100 \mathrm{~ms}$, where the DFIG wind turbine was operating at its rated speed. The circuit breakers on the faulted lines are opened at $200 \mathrm{~ms}$, and finally, at $1000 \mathrm{~ms}$, the circuit breakers are re-closed. The results are shown in Figs. 7-9.

Fig. 7 shows the terminal voltage of the DFIG. It can be observe that, using the CC-VSC based control strategy, the terminal voltage was able to recover faster compared to when the VC-VSC based control scheme was employed. The rotor and wind turbine hub speeds of the DFIG are shown in Fig. 8.
The rotor and wind turbine hub speeds were able to assume their steady state faster after the grid fault with less oscillation when the CC-VSC based scheme was used.

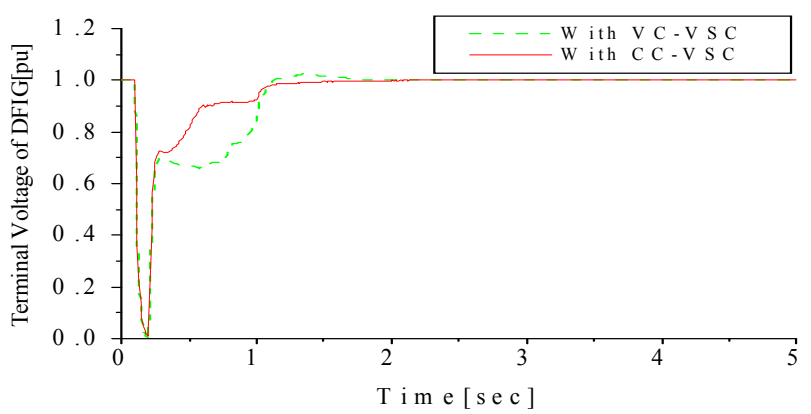

Fig. 7 Terminal voltage of DFIG

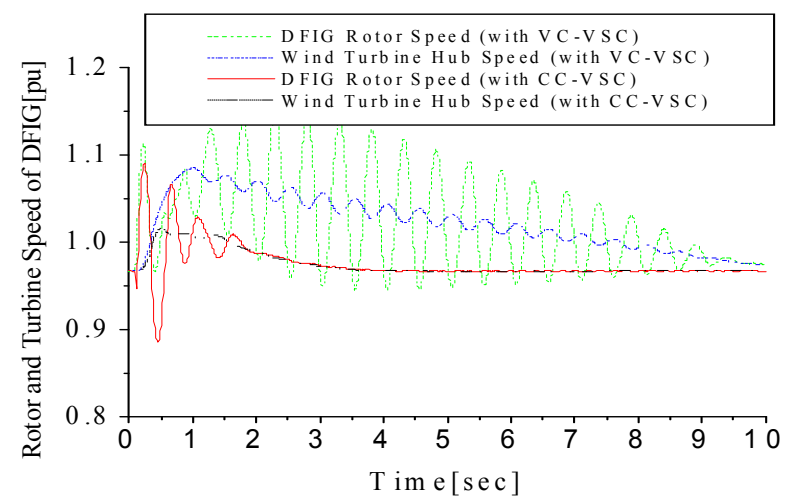

Fig. 8 Rotor and turbine hub speeds of DFIG

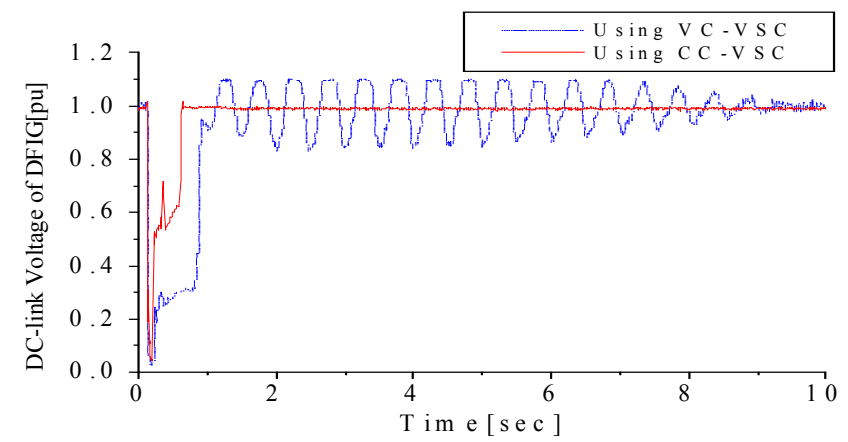

Fig. 9 DC-link voltage of DFIG

The DC-link voltage response for the DFIG using both control strategy is shown in Fig. 9. When the CC-VSC based DFIG control is considered, the overvoltage experienced with the use of the VC-VSC scheme was completely avoided. This is because the CC-VSC based DFIG can effectively control the DC-link voltage of the DFIG during grid fault. Hence, the DClink protection scheme can be omitted for the CC-VSC based DFIG control strategy.

\section{GRID REQUIREMENT}

The grid codes require all wind generators to remain connected to the grid if voltage drop is within the defined value and its duration is also within the defined period as shown in Fig. 10 [21]. The effect of CC-VSC and VC-VSC based DFIG on fixed speed wind turbine (FSWT) with 
induction generator during a $3 \mathrm{LG}$ fault is investigated using the model system in Fig. 11. The one mass model was considered here. All wind generators are operated at their rated power under a constant velocity of $15 \mathrm{~m} / \mathrm{s}$.

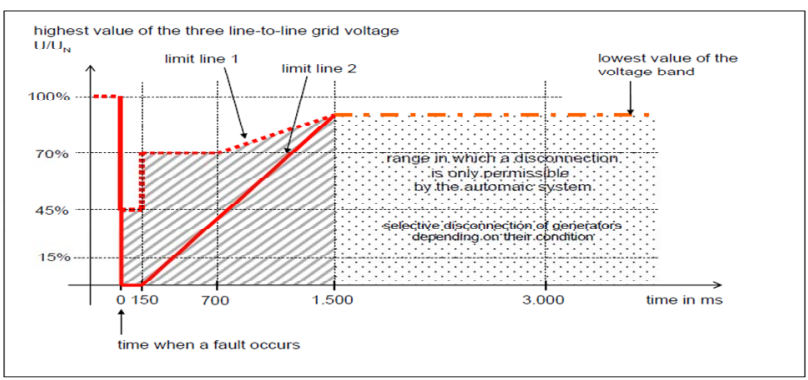

Fig. 10 Fault Ride Through Requirement for Wind Farm

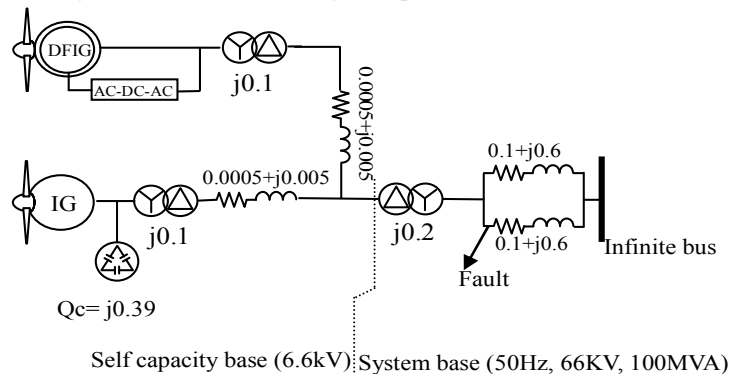

Fig. 11 Simple model system of DFIG and IG

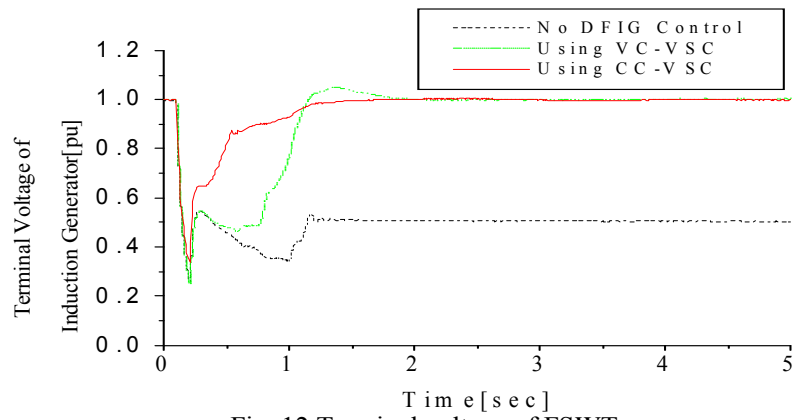

Fig. 12 Terminal voltage of FSWT

It is seen from Fig.12 that, though both schemes can stabilize the FSWT during the grid fault, better performance is achieved in the case of CC-VSC from a point of view of the grid code. On the other hand, when there is no DFIG control, the FSWT becomes unstable.

\section{CONCLUSION}

A comparative study using a current controlled voltage source converter (CC-VSC), and voltage controlled voltage source converter (VC-VSC), in a doubly fed induction generator (DFIG) wind turbine has been carried out. Both schemes can effectively control the DFIG in steady state and transient conditions. However, the CC-VSC is recommended because; it offers the advantages of reduced proportionate integral (PI) controllers at the rotor side of the DFIG, omission of DC-link protective device and less intricacies of controller design. The effectiveness of the recommended CC-VSC based DFIG control method has been verified by simulation analyses for a three line to ground fault (severe case). It has been found that CC-VSC based DFIG gives better performance compared to the use of VC-VSC scheme during transient condition.

\section{REFERENCES}

[1] B. Boukhezzar, and H. Siguerdidjane, "Nonlinear control with wind estimation of a DFIG variable speed wind turbine for power capture optimization," Energy Conversion and Management, vol. 50, pp. 885 892, 2009.

[2] H. Karim-Davijani, A. Sheikjoleslami, H. Livani and M. KarimiDavijani, "Fuzzy logic control of doubly fed induction generator wind turbine," World Applied Science Journal, vol. 6, no. 4, pp. 499-508, 2009.

[3] J. F. Manwell, J. McGowan, A. Rogers, Wind energy explained: thoery design and applications, John Wiley \& Sons; 2002.

[4] F. D. Bianchi, H. D. Battista, R. J. Mantz, Wind turbine control systems: principles modeling and gain scheduling design, $2^{\text {nd }}$ ed., Springer: 2006.

[5] T. Burton, D. Sharpe, N. Jenkins, and E. Bossanyi, Wind energy handbook. John Wiley \& Sons; 2001.

[6] M. B. C. Salles, K. Hameyer, J. R. Cardoso, A. P. Grilo, and C. Rahmann, "Crowbar system in doubly fed induction wind generators," Energies Journal, vol. 3, pp. 738-753, 2010.

[7] M. Lindholm, "Doubly fed drives for variable speed wind turbines," Ph.D Thesis, Technical University of Denmark, 2004.

[8] L. Holdsworth, X. G. Wu, J. B. Ekanayake and N. Jenkins, "Comparison of fixed speed and doubly fed induction wind turbines during system disturbnaces," IEEE Proc. Generatiion Transmission and Distribution 150(3), pp. 343-352

[9] S.M. Muyeen, M. H. Ali, R. Takahashi, T. Murata, J. Tamura, Y. Tomaki, A. Sakahara, and E. Sasano, "Comparative study on transient stability analysis of wind turbine generator system using different drive train," IET Renewable Power Generation, 2, vol. 1, no. 2, pp.131-141, 2007.

[10] "PSCAD/EMTDC Manual”, Manitoba HVDC research center, 1994.

[11] R. Takahashi, J. Tamura, M. Futami, M. Kimura and K. Idle, "A new control method for wind energy conversion system using double fed synchronous generators," IEEJ Trans. Power and Energy, vol. 126, no. 2, pp. 225-235, 2006 (in Japanese).

[12] K.E. Okedu, S. M. Muyeen, R. Takahashi, and J. Tamura, "Stabilization of wind farms by DFIG-based variable speed wind generators," International Conference of Electrical Machines and Systems (ICEMS), Seoul, South Korea, 2010, available online IEEE Explorer.

[13] K.E. Okedu, S. M. Muyeen, R. Takahashi, and J. Tamura, "Comparative study of wind farm stabilization using variable speed generator and FACTS device," IEEE-GCC Conference and Exhibition Dubai, UAE, Feb. 2011, available online IEEE Explorer.

[14] K.E. Okedu, S. M. Muyeen, R. Takahashi, and J. Tamura, "Participation of FACTS in stabilizing DFIG with crowbar during grid fault based on grid codes," IEEE-GCC Conference and Exhibition Dubai, UAE, Feb. 2011, available online IEEE Explorer.

[15] V. Akhmatov, "Analysis of dynamic behavior of electric power systems with large amount of wind power," PhD Thesis, Orsted, DTU, 2003.

[16] J. Niiranen, "Voltage ride through of a doubly-fed generator equipped with an active crowbar," Nordic Wind Power Conference, 2004.

[17] J. Niiranen, "Simulation of doubly fed induction generator wind turbine with an active crowbar," EPE-PEMC, Riga, Latvia, 2004.

[18] K.E. Okedu, S. M. Muyeen, R. Takahashi and J. Tamura, "Comparative study between two protection schemes for DFIG-based wind generator," International Conference of Electrical Machines and Systems (ICEMS), Seoul, South Korea, 2010, available online IEEE Explorer.

[19] M. Yamamoto and O. Motoyoshi, "Active and reactive power control for doubly fed wound rotor induction generator," IEEE Trans. Power Electronics, vol. 6, no. 4, October 1991, pp. 624-629.

[20] B. K. Bose, Power electronics and AC drives, New Jersey: PrenticeHall, pp. 46-52, 1986.

[21]. E.ON NETZ GmbH, Grid connection regulation for high and extra high voltage, 2006. 